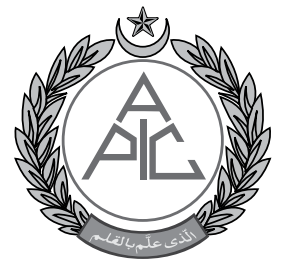

${ }^{1}$ Associate Professor; Postgraduate Resident Department of OMFS, Islamic International Dental Hospital, Islamabad (Pakistan) ${ }^{3}$ Consultant, Department of OMFS, Combined Military Hospital, Rawalpindi (Pakistan)

\section{Correspondence:}

Dr. Jawaria Bibi, PGT, OMFS Department, Islamic International Dental Hospital, G-7/4, 7th Avenue, Islamabad (Pakistan); Cell: 03325251491; E-mail: jawaria.sayyed@gmail. com

Received: 30 Sep 2018

Reviewed: 16 Nov 2018

Accepted: 17 Nov 2018

\title{
Intubation concerns in maxillofacial trauma patients
}

\author{
Kamran Khan, BDS, MFDS, FFD RCSI (OMFS) ${ }^{1}$, \\ Jawaria Bibi, BDS, PGT FCPS 11 (OMFS)2, \\ Muhammad Umar Qayyum, BDS, FCPS (OMFS) ${ }^{3}$
}

\begin{abstract}
Introduction: In maxillofacial trauma the preferred intubation method for general anesthesia is nasotracheal intubation in most of the trauma centers. We conducted a retrospective study to review the utility of this method of intubation in maxillofacial trauma patients. We aimed to review the intra-operative and postoperative concerns and complications for nasotracheal intubation and effectiveness of this method of intubation in maxillofacial trauma patient.
\end{abstract}

Methodology: This study included 56 patients of maxillofacial trauma, who were treated in our centre of Oral and Maxillofacial Surgery at Islamic International Dental Hospital, Islamabad in the period of two years, 1st January 2016 to 31st December 2017.

Results: The study showed that nasal intubation is relatively more effective in isolated mandibular trauma patients. But there are difficulties regarding intubation in maxillary fractures and pan-facial trauma patients.

Conclusion: Although nasotracheal method of intubation is difficult to attain in some cases, but still it is an effective method of intubation for majority of the maxillofacial trauma cases with very low rate of complications.

Key words: Trauma, Maxillofacial; Nasotracheal intubation; Trauma; Trauma, Pan-facial

Citation: Khan K, Bibi J, Qayyum MU. Intubation concerns in maxillofacial trauma patients Anaesth Pain \& Intensive Care 2018;22 Suppl 1:S109-S112

\section{INTRODUCTION}

Airway management is primary concern in patients with maxillofacial injuries. It is very challenging because airway compromise can cause hypoxia in early stages, leading to airway obstruction later. ${ }^{1}$ In polytrauma patients definitive care is to provide advanced airway management in hospital settings. About $20 \%$ to $30 \%$ intubations in the hospital emergency department are for trauma patients. ${ }^{2,3}$ In patients with maxillofacial trauma maintaining the airway is important in early stages and then in later stages. Surgical repair can be dealt with anesthesia. ${ }^{1}$

In patients with maxillofacial trauma, facial injuries may include minor lacerations to severe brain injury. Facial fractures may involve facial skeleton and skull base. While surgically repairing these injuries in stable post trauma patients, most commonly used method for anesthesia is nasotracheal intubation. Because endotracheal intubation cannot be used as it interferes with the MMF and occlusion. ${ }^{1}$ In surgical procedures related to oral cavity, pharynx, larynx and also neck, nasotracheal intubation provides more room for surgeon to surgical field. ${ }^{4,9}$

The technique for nasotracheal intubation was first introduced by Khun in 1902. Afterwards Magill used this technique for oral surgery in the period of 1920s. It had been used for the patients requiring 
prolonged intubation in intensive care settings. ${ }^{4} \mathrm{At}$ that time the most commonly reported complication was risk of sinusitis, that limited the use this method of intubation. Traumatic intubation can cause inflammatory edema, which may obstruct Eustachian duct resulting in middle ear problems or may result in sinusitis due to blockage of sinus ostium. ${ }^{4}$

One of the common complication to nasal intubation is epistaxis due to damage to Kisselbach's plexus in anterior nasal septum area.,9 Traumatic intubation can damage the nasal cavity that may cause avulsion of nasal polyps, turbinates fracture or septal abscess. Other complications may include aspiration of nasal contents, vagal stimulation, laryngospasm, vocal cord damage, bacteremia due to nasal flora ${ }^{9}$ and pneumothorax.

In patients with severe trauma having mid face fractures and fracture of base of the skull, blind nasotracheal intubation can cause serious brain injury. ${ }^{8,5}$ There is a relative contraindication for nasal intubation in such cases. ${ }^{8}$

Oral endotracheal intubation also serves the purpose in isolated nasal fractures where occlusion is not disturbed. In maxillofacial trauma patients dealing with fractures of mid-face and mandible, occlusion is disturbed in majority of the cases that precludes the use of endotracheal intubation. ${ }^{8}$

Fiber optic intubation is a relatively preferred method of intubation in cases where blind nasal intubations needed or where endotracheal intubation is difficult anatomically. ${ }^{5}$ But this requires expensive equipment and skilled anesthetist. ${ }^{9}$

Submental intubation is another alternative technique for intubation in trauma patients who have nasal fractures along with other facial fractures disturbing the occlusion. It is a safe method with relatively low complications. ${ }^{6}$

The purpose and aim of this study is to evaluate the significance of nasotracheal intubation in patients with maxillofacial trauma considering the advantages and complications faced both intraoperatively and postoperatively.

\section{METHODOLOGY}

A retrospective study conducted at oral and maxillofacial surgery department of Islamic international dental hospital, Islamabad. A total number of 56 cases were reviewed in this study who were admitted in the centre and treated surgically for maxillofacial trauma in the period of two years from 1st January 2016 to 31st December 2017. The trauma patients who had blind nasotracheal intubation for general anesthesia to undergo surgery for facial fractures were the part of study. All patients with any type of facial fractures like isolated mandible fractures, midface fractures, orbital fractures and panfacial fractures were studied. It included patients of age group 18 to 40 years old. Patients who underwent surgery with intubations other then blind nasal intubation were excluded from the study.

Complications due to nasal intubation were recorded as separate variables during intra operative period and immediate postoperative period of three days. It included epistaxis, nasal cavity damage, throat pain and maxillary sinusitis. Epistaxis was considered for continuous nasal bleed from nose in intra operative or postoperative period. Nasal cavity damage included nasal septal abscess and nasal bone fracture accessed by postoperative radiographs. Throat pain and discomfort was accessed from patients postoperative complaints, recorded in postoperative period. Sinusitis was another variable studied which was also accessed from postoperative radiographs. Complications reported for every patient, were recorded from the hospital data.

Ethical clearance certificate was obtained from ethical committee of Islamic International dental hospital, Islamabad.

\section{RESULTS}

We reviewed retrospective data of 56 patients including 37 males and 19 females. Among them 10 patients were of panfacial trauma and 32 were of isolated mandibular fracture. There was highest number of patients with isolated mandibular fractures, including symphysis, parasymphysis, angle, body of mandible and condylar fractures. Details are given in Table 1. Epistaxis was reported in 09 cases. As all patients under went blind nasal intubation, retro pharyngeal dissection resulting in postoperative pain and discomfort was reported in highest number as complication. The 13 out of 56 patients complained for pain and discomfort in throat during postoperative period. Complications reported due to intubation are showed in Table 2.

The results showed that there was $16.07 \%$ of cases who had one or more episodes of epistaxis after intubation. As shown in table 2, out of 09 reported

Table 1: Frequency of different types of facial fractures

\begin{tabular}{l|c}
\hline Type of facial fracture & No. Of patients \\
\hline Isolated mandibular fracture & 32 \\
\hline Mid-face fracture & 14 \\
\hline Pan facial fracture & 10 \\
\hline
\end{tabular}


cases 03 patients were of mid face fracture, 05 of pan facial trauma and 01 of isolated mandibular fracture. There were $23.21 \%$ cases reported for postoperative throat pain and discomfort.

There were no reported cases of any of the other complications including nasal cavity damage and sinusitis of maxillary sinuses.

\section{DISCUSSION}

Securing the airway in patients with maxillofacial trauma is challenging. After initial emergency care, patient is prepared for surgical repair of facial injuries. Different types of intubations have been used to secure airway in both immediate and late stages of treatment of these patients. Nasotracheal intubation is been used commonly for head and neck surgeries as this tube provides efficient room for surgeon to work intraorally. ${ }^{4,9}$

Studies recommend the preference of nasal intubation over endotracheal tube, as it makes surgeons job easier. ${ }^{8}$ It provides better surgical access to the operating site and establishing occlusion becomes easier. ${ }^{1,8}$ Submental intubation is also recommended especially in cases where nasotracheal tube would not serve the purpose, as in NOE (naso-orbito-ethmoidal) fractures. ${ }^{6}$

In Maxillofacial trauma patients facial injuries are followed by excessive inflammation and swelling of facial soft tissues. It is suggested that extubation in such patients should be delayed until edema subsides. ${ }^{8}$ this is also helpful in preventing the aspiration of gastric contents because of nausea and vomiting. ${ }^{8}$

Studies showed that the most commonly occurring complication due to nasal intubation is epistaxis that occurs when nasal tube damages the nasal mucosa along its passage, ${ }^{4,9,12}$ with the incidence of $18 \%$ to $66 \%{ }^{10}$

Other complications like injury to nasal cavity is also reported in studies. Nasal injury may result in damage to inferior turbinate. ${ }^{13}$

In blind nasal intubation there is high chance for retro pharyngeal dissection, and is also reported as complication after nasotracheal intubation. ${ }^{10,11-}$

Lee and Haung in 2009, studied and compared the different methods of intra-operative intubation in maxillofacial trauma patients. ${ }^{12}$ They studied the time taken by endotracheal, nasotracheal and fibre-optic nasal intubation in patients with facial fractures. The mean time for nasotracheal intubation was reported 5 minutes with 69.4 seconds for tube passage. It was longer than time taken by endotracheal intubation but shorter than fibre-optic nasal intubation. ${ }^{12}$

We studied retrospective data of complications due to nasotracheal intubation in 56 patients of maxillofacial trauma in our centre.

The major complication reported was epistaxis, was $16.07 \%$. Nasal bleeding occurred in 09 patients with higher incident in mid face and pan-facial trauma cases. Mobile mid-facial bones and unstable mandible made nasal intubation more traumatic and difficult. When passage of nasal tube is more traumatic, there is high chance of damage to nasal mucosa and Kisselbach's plexus resulting in epistaxis.

We found no case of postoperative sinusitis and nasal cavity damage in past record of two years.

Other then these, $23.21 \%$ cases were reported for postoperative throat pain and discomfort that was possibly due to retropharyngeal dissection by nasal tube, which could be a consequence of blind nasal intubation.

We studied retrospective data of limited number of patients. The data was collected from the hospital records which were not complete for every single case. We had also lost follow up in some cases which limited our study.

\section{CONCLUSION}

Patients with maxillofacial trauma have difficult airway management. When patient is prepared for surgery the preferred method of intubation is nasotracheal, as it provides benefits of easy access to surgical field and a very low rate of complications. The naso- tracheal intubation showed very low rate of complications in our study and better results in different type of facial fractures. This method of intubation has been used in our system for past many years and is equally effective today.

Conflict of interest: The authors declare that they have no conflict of interest.

\section{Authors' contribution}

All authors took part in conduction of cases and writing manuscript

KK-Concept and leader of project 


\section{REFERENCES}

1. Mohan R, Lyer R, Thaller S. Airway Management in Patients With Facial Trauma. J Craniofac Surg. 2009 Jan;20(1):21-3. [PubMed] DOl: 10.1097/SCS.0b013e318190327a

2. Kovacs G, Sowers N. Airway management in trauma. Emerg Med Clin North Am. 2018;36(1):6184. [PubMed][Free Full Text] DOI: 10.1016/j.emc.2017.08.006

3. Kerslake D, Oglesby AJ, Di Rollo N, James E, McKeown DW, Ray DC; EDIR investigators. Tracheal intubation in urban emergency department in Scotland: A prospective, observational study of 3738 intubations. Resuscitation. 2015;89:20-4. [PubMed] DOl: 10.1016/j.resuscitation.2015.01.005

4. Hall CEJ, Shutt LE, Nasotracheal intubation for head and neck surgery. Anaesthesia. 2003 March; 58(3):249256. [Free Full Text]

5. Rosen CL, Wolfe ER, Chew SE, Branney SW, Roe EJ. Blind nasotracheal intubation in the presence of facial trauma, panel. J Emerg Med. 1997:15(2):141-5. [PubMed][Free Full Text]

6. Lima SM Jr, Asprino L, Moreira RW, de Moraes M. Retrospective Analysis of Submental Intubation in Maxillofacial Trauma Patients. J Oral Maxillofac Surg. 2011 Jul;69(7):2001-5. [PubMed] doi: 10.1016/j.joms.2010.10.017.

7. Shatney $\mathrm{CH}$, Jose $\mathrm{S}$, Brunner RD, Nguyen TQ. The Safety of Orotracheal Intubation in Patients With Unstable Cervical Spine Fracture or High Spinal Cord Injury. Am J Surg. 1995 Dec;170(6):676-9. [PubMed][Free Full Text]

8. Barak $M$, Bahouth $H$, Leiser $Y$ and El-Naaj IA. Airway Management of the Patient with Maxillofacial Trauma: Review of the Literature and Suggested Clinical Approach. Biomed Res Int. 2015 Jun 16; 2015: 724032 [Free Full Text]

9. Prasanna D, Bhat S. Nasotracheal Intubation: An Overview. J Maxillofac
Oral Surg. 2014 Dec ;13(4):366-72. [Free Full Text]

10. Piepho T, Thierbach A, Werner C. Nasotracheal intubation: look before you leap. Br J Anaesth. 2005 Jun;94(6):859-60.. [PubMed] [Free Full Text]

11. Garth RJ, Brightwell AP. A comparison of packing materials used in nasal surgery. Laryngol Otol. 1994 Jul; 108(7):564-6.

12. Lee SS, Huang SH, Wu SH, Sun IF, Chu KS, Lai CS, et al. A Review of Intraoperative Airway Management for Midface Facial Bone Fracture Patients. Ann Plast Surg. 2009 Aug: 63(2):162-6. [PubMed] doi: 10.1097/ SAP.0b013e3181855156.

13. Moghaddas OPJ, Tse W, Herzing KA, Markert RJ, Gans AJ, McCarthy MC. Is nasotracheal intubation safe in facial trauma patients? Am J Surg. 2016;213(3):572-574. DOI: https://doi.org/10.1016/j. amjsurg.2016.11.003 